Chapman University

Chapman University Digital Commons

7-1999

\title{
Strategic Flexibility In Information Technology Alliances: The Influence Of Transaction Cost Economics and Social Exchange Theory
}

Candace Ybarra

Chapman University, cybarra@chapman.edu

Margarethe Wiersema

University of California - Irvine

Follow this and additional works at: https://digitalcommons.chapman.edu/business_articles

Part of the Business Commons, and the Economic Theory Commons

\section{Recommended Citation}

Young-Ybarra, Candace, and Margarethe Wiersema. "Strategic flexibility in information technology alliances: The influence of transaction cost economics and social exchange theory." Organization Science 10.4 (1999): 439-459.

DOI:10.1287/orsc.10.4.439

This Article is brought to you for free and open access by the Business at Chapman University Digital Commons. It has been accepted for inclusion in Business Faculty Articles and Research by an authorized administrator of Chapman University Digital Commons. For more information, please contact laughtin@chapman.edu. 
Strategic Flexibility In Information Technology Alliances: The Influence Of

Transaction Cost Economics and Social Exchange Theory

\section{Comments}

This article was originally published in Organization Science, volume 10, issue 4, in 1999. DOI: 10.1287/ orsc.10.4.439

\section{Copyright}

Institute for Operations Research Management Sciences 


\title{
Strategic Flexibility in Information Technology Alliances: The Influence of Transaction Cost Economics and Social Exchange Theory
}

\author{
Candace Young-Ybarra • Margarethe Wiersema \\ Argyros School of Business and Economics, Chapman University, Orange, California 92866, \\ cybarra@chapman.edu \\ Graduate School of Management, University of California, Irvine, Irvine, California 92697-3125, mfwierse@uci.edu
}

\begin{abstract}
Tn the literature on strategic alliances, trust is often positioned as the magic ingredient in alliance success. Typically, trust is treated in the literature as a residual term in the statistical models, neither operationalized nor measured. This paper is important because it operationalizes and measures trust as a multidimensional construct, which is both causally antecedent to strategic alliance, flexibility, and the outcome of characteristics of the alliance partners. I believe the field needs more theoretical and empirical precision regarding trust, as exemplified in this paper.
\end{abstract}

Mitchell P. Koza

\begin{abstract}
Utilizing a model drawn from both transaction cost economics and social exchange theory, we analyze determinants of strategic flexibility in a sample of strategic alliances involved in joint development agreements or joint research pacts. Findings indicate that, in general, determinants suggested by transaction cost economics provided flexibility in modification and inflexibility in exit. From social exchange theory, trust was found to be positively related to both types of flexibility while another component of social exchange theory, dependence, was found to be negatively related to the strategic flexibility of the alliance. Results also found that factors suggested by both transaction cost economic theory and social exchange theory were related to the concept of trust. Economic constraints as suggested by transaction cost economics were positively related to trust between the alliance partners while dependence was negatively related to trust. Additionally, the quality of communication and the existence of shared values were positively related to trust between the exchange partners. Results provide support for the role of determinants from both transaction cost economics and social exchange theory in the flexibility of strategic alliances. (Strategic Alliances; Flexibility; Trust)
\end{abstract}

The emergence of new global competitors, the convergence of high-technology industries, and the increasing speed and cost of technological development promise an increasingly uncertain environment for firms (Hagedoorn and Schakenraad 1994). These dynamic competitive forces call for organizations to be efficient, innovative, and flexible (Duncan 1976), suggesting that processes for ensuring strategic flexibility may be a crucial element of strategic management (Evans 1991). This may be particularly true in fast-paced industries or hypercompetitive environments characterized by rapid technological change, shortened product life cycles, increasing competitive rivalry, and global competition (Volberda 1996). Many organizations have found that it is almost impossible to address these competitive forces without some major internal and external structural adjustments that provide greater strategic flexibility.

Faced with greater environmental uncertainty, firms may want to avoid long entanglements that could prove to be wrong later and will instead favor more flexible, less binding relationships (Crocker and Masten 1988) such as strategic alliances. Interorganizational relationships such as strategic alliances provide the firm with greater ability to pursue new developments in technologies, products, and markets and thus allow it to initiate or adapt to competitive change (Volberda 1996). Porter and Fuller (1986) argue that partnerships and collaborations are a more rapid means of competitive repositioning 
than internal development, and are less costly and more flexible than mergers. Similarly, Balakrishnan and Koza (1995) view joint ventures as transitional, short-lived strategies. Support for these arguments comes from Kelly and Amburgey (1991), who distinguish between core and peripheral activities within a firm and provide evidence that in uncertain situations where change may be necessary, the firm will benefit by utilizing peripheral devices, such as strategic alliances.

The rate of alliance formation has increased, particularly in high-technology industries where R\&D is characterized by substantial uncertainty (Hagedoorn and Schakenraad 1992). And yet, research examining alliance formation and failure have found that anywhere from $30 \%-70 \%$ of alliances are considered failures by one or more of the partners or break up prematurely (Fortune 1992). As such, increasing scholar attention on the subject of strategic alliances has led to research examining the motives for collaboration (Hladik 1988, Oliver 1990) and the governance structure of these alliances (Gulati, 1995, Zaheer and Venkatraman 1995), as well as the factors that lead to their success (Mohr and Spekman 1994, Parkhe 1993), stability (Anderson and Weitz 1989; Heide and John 1988, 1990), or continuity (Olk and Young 1997).

As a result of the failure of many alliances, understanding the factors related to their success or continuity has become an important subject of investigation. Because of the rapidity and frequency with which environmental changes occur, the benefit or success of a strategic alliance may be closely associated with its strategic flexibility and the ability to adjust the relationship to changes, including the timely termination of the relationship when the alliance no longer meets the partners' needs (Niederkofler 1991). Thus, the flexibility of a strategic alliance has been argued to be one of the key factors related to the success or "usefulness" of an alliance (e.g., Porter and Fuller 1986, Harrigan, 1986). However, because few studies have been systematically designed to study flexibility in a strategic alliance setting (Fiegenbaum and Karnani 1991), there appears to be a need to examine the underlying factors that lead to strategic alliance flexibility.

This study attempts to address these shortcomings by utilizing a comprehensive framework wherein both transaction cost economics and social exchange theory are used to examine two elements of strategic flexibility in strategic alliances: the flexibility to modify the alliance and the flexibility to exit the alliance relationship when the alliance is performing poorly. This model is investigated within a sample of strategic alliances representing joint development or joint research pacts on information technology. Analytical techniques are utilized that allow for the simultaneous estimation of the relationship between underlying factors suggested by transaction cost economics and social exchange theory and the flexibility of a strategic alliance.

\section{Determinants of Strategic Alliance Flexibility}

\section{Strategic Flexibility}

In a dynamic and turbulent environment, strategic decisions may need to be continually reexamined. Responding to a wide variety of changes in the competitive environment necessitates an adaptive capability or flexibility on the part of the organization (Volberda 1996). Strategic flexibility is generally considered to be a construct with multiple dimensions (Evans 1991) and has been defined as the ability to adapt to environmental changes (Aaker and Macarenhas 1984), to change game plans (Harrigan 1985), to precipitate intentional changes, to continuously respond to unanticipated changes, and to adjust to the unexpected consequences of predictable changes (Bahrami 1992).

In the strategic alliance literature, two general types of flexibility have been specified: modification and exit. The first, modification, refers to the ability of partners to adjust their behaviors or the terms of the agreement in response to changes in the environment or to the needs of their partners (e.g., Heide and John, 1992). Given bounded rationality, it is impossible to contractually specify every possible contingency involved in managing a strategic alliance (Williamson 1985). Thus, the eventual viability and success of the alliance may depend on the ability of partners to observe and respect informal obligations of the relationship and to modify the terms of the alliance (formal or informal) for continued value creation.

The second type of strategic flexibility is the relative ease of exit from an alliance in which the partner is no longer satisfied or that no longer meets the partner's needs. According to Harrigan and Newman (1990), the needs and strengths of each partner in a joint venture are subject to constant change. These changes, then, often enhance or diminish that partner's interest in the alliance's activities. As such, the flexibility to be able to terminate or exit from the relationship becomes an important strategic concern for individual partners in alliances.

\section{Determinants of Strategic Flexibility}

Two theoretical perspectives were utilized in developing models of strategic flexibility-transaction cost economics and social exchange theory. Transaction cost economics has been found to be a useful theoretical perspective 
from which to examine many facets of strategic alliances, including structure (Gulati 1995), continuity (Olk and Young 1997), and stability or survival (Parkhe 1993). According to transaction cost theory, partners within strategic alliances are assumed to have the potential for opportunistic behavior. Thus, it is necessary to secure commitment to the alliance through the investment of specific assets and other types of economic "hostages" (Parkhe 1993, Williamson 1985).

While economic theories have been used to explain intra- and interorganizational phenomena, there is currently a growing debate between economists and behavioralists about the extent to which economic analyses alone extend our knowledge of organizations (Barney 1990, Donaldson 1990). Organization theorists have challenged the assumptions underlying economic models that often overlook trust and power and exaggerate the influence of opportunism in organizations (Jones 1983, Perrow 1981). Consequently, although economic models have predominantly been used to examine the nature of strategic alliances, researchers have argued that social exchange theory may be a more useful theoretical perspective for the investigation of strategic alliances (Graham 1988).

In addition to factors suggested by transaction cost economics, social exchange theorists consider it important to understand the social context in which those decisions are made (e.g., Cook 1977, Cook and Emerson 1978, Granovetter 1985). Trust represents one such important social context factor. As Granovetter explains, many attempts at rational, economic action are really "embedded" in social relations, and he stresses "the role of concrete personal relations and structures of such relationships in generating trust and discouraging malfeasance" (1985, p. 490). In addition, the dependence of organizations on each other as suggested by both social exchange theorists (e.g., Blau 1964) and organization theorists (e.g., Pfeffer and Salancik 1978) represents another important social context factor.

Transaction cost economics and social exchange theory together may provide a more comprehensive explanation of the strategic flexibility of alliances. In addition, the interrelationships among the theoretical determinants of flexibility may provide an even more thorough understanding of strategic alliance flexibility.

\section{Transaction Cost Economics and Strategic Flexibility}

According to transaction cost economics, the costs associated with various organizational structures constitute the critical factor determining the choice of transacting mode. Transaction cost theory has been used to address many issues related to strategic alliances, including commitment (e.g., Parkhe 1993) and stability (e.g., Heide and John 1988, 1990). Partners within strategic alliances are assumed to have the potential for opportunistic behavior (Reich and Mankin 1986). Transaction cost economists have recognized the proliferation of these intermediate governance structures and suggest that they are maintained by economic weapons such as hostages and other credible economic commitments. The effect of such economic commitments is to create a locked-in condition (Katz 1989) which in turn promotes behaviors that ensure the continuance and "mutual forbearance" of the partnership (Buckley and Casson 1988). Specifically, economic constraints such as the investment of specific assets and hostage arrangements may be utilized to reduce the potential for opportunism by locking partners into a strategic alliance with the expected long-term gains from maintaining the relationship exceeding the potential short-term gains from opportunism or defection (Parkhe 1993, Williamson 1985). We examine three factors suggested by transaction cost economics as determinants of an alliance's flexibility: asset specificity, balanced asset specificity, and hostages.

Asset Specificity. Asset specificity refers to the nature of the transferability of assets from one use to another. "Specific assets are those whose value is less if switched to alternative transactions and consequently whose value is not fully salvageable if the relation breaks down" (Lorenz 1988, p. 199). As assets are created or modified for a particular use, they may have severely diminished value in other settings. Thus, as Klein et al. (1978) have argued, firms become locked into a course of action when investments in specific assets have been made.

Asset specificity may serve to tie members together by subverting the flexibility of pursuing other alternatives or severing the interorganizational relationship. An organization may become locked in to an alliance with another company as it devotes more assets to the relationship. These idiosyncratic investments lose value upon transfer, so exchange partners may become committed to making the existing relationship succeed (Parkhe 1993, Williamson 1985). This may be particularly true for intangible factors such as managerial skills and technical know-how. Thus, intangible asset specificity should prove to have a much more significant influence on the strategic flexibility of the alliance. Consequently, firms may find it in their own best interest to continue the relationship due to their investments in the alliance (Heide and John 1992, Parkhe 1993). To protect these investments, firms may be more willing to be flexible in terms of modifying the agreement rather than causing it to fail by being unwilling to adjust. 
In an intraorganizational context, specific assets have been found to bind organizations to a particular strategy or course of action. Ghemawat (1991) described this phenomenon as "lock-in." Assets created or purchased for the purpose of a particular strategic course of action may not be easily transferable to other courses of action. As such, these assets may lead to lock-in even when the alliance is no longer satisfying the partner. Lei and Slocum (1992), for instance, argue that strategic alliances can serve to increase dependence on other firms if the organization, through heavy involvement, gives away its own skills and know-how without learning from the partner. In the case where these commitments to the relationship are based on contractual specifications or other economic constraints, the flexibility to exit the relationship even when it no longer fits the needs of the partner may be difficult.

As a result of the above discussion, it is proposed that the investment of specific assets into the alliance will be positively related to flexibility in modifying the terms of the alliance agreement, but negatively related to exit flexibility.

HYPOTHESIS 1a. Asset specificity is positively related to the strategic flexibility of an alliance, measured in terms of modification.

HYPOTHESIS 1b. Asset specificity is negatively related to the strategic flexibility of an alliance, measured in terms of exit.

Balanced Asset Specificity. Balanced asset specificity refers to the extent to which each partner has contributed equal levels of specific assets to the alliance. While previous research has separately examined the specificity of the assets contributed by each partner to the exchange (Zaheer and Venkatraman 1995), this study utilizes the concept of balanced asset specificity that is a unique attribute of the dyadic relationships examined here. This conceptualization of specific assets invested explores more fully the mutual commitments that may exist between partners in an alliance. One strategy for creating a self-enforcing agreement is for both parties involved to make "credible commitments" to the relationship (Williamson 1985), for example, by means of investments in specific assets (Anderson and Weitz 1989) or other relationships with the partner (Kogut 1989). Because alliances are mediated only partly through prices, parties demand mutual commitments from their partners in the form of alternative or complementary technology, market information or access, as well as reputation or credibility (Mody 1993). A dependence condition exists (Barney and Ouchi 1986) which, if balanced, represents a mutual safeguard (Williamson 1985) and a collective incentive to maintain the relationship.

The general incentive to maintain the relationship can manifest itself in different ways. One specific outcome of this balance of assets contributed is that the parties will have a joint motivation to show "forbearance" (Buckley and Casson 1988) or flexibility in response to changing circumstances. The existence of balanced investments serves to align the respective parties' interests and promotes flexibility as a means of preserving the relationship (Heide 1994). Thus, it is proposed that the existence of balanced asset specificity will be positively related to flexibility in modifying the terms of the alliance agreement.

HYPOTHESIS 2. Balanced asset specificity is positively related to the strategic flexibility of an alliance, measured in terms of modification.

Hostages. Hostage arrangements refer to the existence of other current relationships between the partners to the focal alliance. These hostages are another type of safeguard discussed in transaction cost economics as a protection against a partner's opportunistic behavior (Williamson 1983). The utilization of hostages as a safeguard implies that there is the possibility of penalties for any opportunistic behavior on the part of the partners involved. Researchers have argued that "mutual forbearance" (refraining from cheating) is necessary in maintaining strong current relations (e.g., Buckley and Casson 1988). The existence of other current relationships (i.e., hostages) is one method for facilitating that mutual forbearance. Hostages, then, can be in the form of other current alliances or the expectation of entering into other relationships in the future.

Williamson (1985) proposed that organizations involved in more than one alliance with the same partners have created a "mutual hostage" arrangement. Here, the failure of one relationship may threaten the strength or viability of others. Kogut (1989) provided empirical support for the strength of multiple ties. He found that involvement in more than one collaborative relationship led to the stability of the focal joint venture.

As a result, alliance members with multiple current relationships among themselves are considered to have economic hostages and are less likely to sever the focal alliance relationship and are more likely to be willing to modify the existing relationship in order to ensure its survival. Consequently, it is proposed that hostage arrangements (multiple relationships) will be positively related to flexibility in modifying the alliance and will be negatively related to flexibility in exiting the alliance. 
HYPOTHESIS 3a. The existence of hostage arrangements is positively related to the strategic flexibility of an alliance, measured in terms of modification.

HYPOTHESIS 3b. The existence of hostage arrangements is negatively related to the strategic flexibility of an alliance, measured in terms of exit.

\section{Social Exchange Theory and Strategic Flexibility}

Social exchange theory suggests that two specific aspects of organizational context may be influential in understanding the flexibility of relationships between organizations. First, that the trust between the organizations will have a positive impact on the desire and ability of the partners to adjust to changing environmental demands through modification or termination of the agreement (Lorenz 1988, Mody 1993). Second, that the dependence of the partner on the alliance may also be an important factor that influences the flexibility in using a strategic alliance. In general, researchers have argued that dependency may serve to commit the partner to the alliance, thereby increasing the longevity of the relationship (Parkhe 1993).

Trust. Researchers in sociology and organization theory have emphasized the importance of trust in social and economic exchange. While the study of trust has its roots in psychology and social psychology and is intuitively an interpersonal phenomenon, with many sociologists arguing that expectations of trust do ultimately reside within individuals, many management scholars have taken this idea of interpersonal trust and extended it to the organizational level (e.g., Gulati 1995, Zaheer et al. 1998). Justification for this extension of interpersonal trust to the organizational level comes from many sources. For example, Ring and Van de Ven (1994) argue that although the individuals within an organization may be transitory, their role definitions are stable and enduring. The trust, then, may reside within the roles and routines of the organization and not necessarily with only the individual. Recently, the concept of trust has been utilized in the study of joint ventures (e.g., Gulati 1995) and in the marketing channels literature to examine governance (e.g., Zaheer and Venkatraman 1995) and commitment (Morgan and Hunt 1994). Anderson and Narus (1990) suggest that once trust is established, firms learn that joint efforts will lead to outcomes that exceed what the firm would achieve had they acted solely in their own best interests.

While trust has been defined in many different ways to address many different organizational research questions, one that is consistent with research on interorganizational relationships is that of Dodgson (1993), who defined trust as a state of mind, an expectation held by one trading partner about another, that the other will behave in a predictable and mutually acceptable manner. As suggested by Koza and Lewin (1998), "for trust to be a useful concept its principle components must be identified, operationalized and measured" (p. 259). Thus, to capture the multidimensionality of the concept of trust, similar to Zaheer et al. (1998), we characterize trust as a construct based on three components-dependability, predictability, and faith. Dependability refers to expectations that the partner will act in the alliance's best interest, predictability refers to consistency of actions by the partner, while faith refers to the belief that the partner will not act opportunistically, even in unforeseen or novel situations.

It has been argued that trust is so important to relational exchange that it is considered to be a central feature of a strategic partnership (Mohr and Spekman 1994). Because investments in alliances entail a vulnerability, parties will seek ways to partner with partners that exhibit characteristics of dependability and predictability, even in unforeseen situations (faith). In the literature on interorganizational relationships, there has been a somewhat consistent argument that the existence of relationships based on the trust between partners has a positive impact on the ability of the partners to adjust to changing environmental demands or unintended problems that may arise. For example, Lorenz (1988) argues that partnerships that exhibit trust will survive greater stress and will display greater adaptability. Similarly, in examining the evolution of cooperative arrangements, Doz (1996) found that alliances that have developed trusting relationships over time are more likely to be adaptable and to survive for longer periods of time. Thus, relationships based on trust, as measured by dependability, predictability, and faith, should exhibit more flexibility in decision making and operations than those that are not.

In addition, as the needs and strengths of each partner in its major activities are subject to continual change, the partners' interest in the strategic alliance may diminish. If a relationship exhibits trust, but confronts dramatic changes in the market indicating that the alliance should be dissolved, partners may break up that particular alliance but form a new one (Mody 1993). As a result of the arguments above, it is proposed that trust between organizations in an alliance, as indicted by the partner's perception of dependability, predictability, and faith, will be positively related to flexibility in both modification and exit.

HYPOTHESIS 4a. Trust is positively related to the strategic flexibility of an alliance, measured in terms of modification. 
HYPOTHESIS $4 \mathrm{~b}$. Trust is positively related to the strategic flexibility of an alliance, measured in terms of exit.

Dependence. In addition to trust, power and its corollary dependence are important elements in social exchange. Imbalances of obligations incurred in transactions produce differences in power and arise in the course of competition for scarce goods (Blau 1964). According to Blau (1964) power may be defined as:

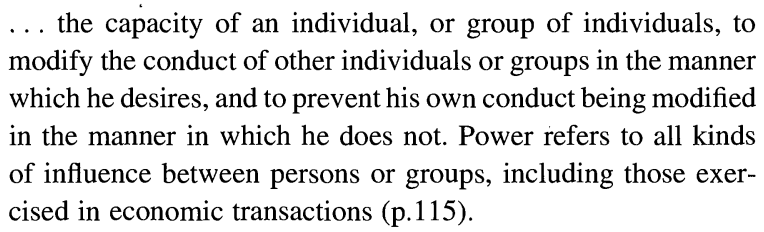

By supplying demanded services to others, a person can establish power over others. And, if those services cannot be obtained elsewhere, dependence will emerge.

Social exchange theorists (e.g., Blau 1964) and organization theorists (e.g., Pfeffer and Salancik 1978) have built on a model of "power-dependence" developed by Emerson (1962). Resource dependence theory has argued that an organization acts to reduce environmental uncertainty (Pfeffer and Salancik 1978). Uncertainty is generated by resource scarcity and by a lack of perfect knowledge about environmental fluctuations and availability of exchange partners (Cook 1977). Under conditions of resource scarcity, one method for attaining the goal of uncertainty reduction is through the use of interorganizational exchanges (Levine and White 1961). An alliance may be particularly important when no alternatives for reduction of uncertainty or dependence are available. In their study of the relationships and linkages in the health care industry, Levine and White (1961) argued and found that interdependence will be even greater for those organizations that do not have the ability to obtain their resources and hence reduce their uncertainty outside of the current network of relationships. In this case, the alliance may be sustained simply to help in uncertainty reduction, even though performance from the relationship is not enhanced.

In examining the dependence of organizations on each other, Pfeffer and Salancik (1978) argue that dependence is made up of three elements: (1) importance of the resource being obtained, (2) the discretion of the use of the resource, and (3) the absence of alternatives for obtaining the resource. Building on this work, Heide and John (1988), in their study of dependence balancing in marketing channels, expand the notion of fewer alternatives to include both fewer current alternatives as well as fewer potential alternatives.
The options approach proposed by Kogut (1991) develops the perspective that joint ventures are created as "real options" to expand into future technological developments or markets. Because these options offer flexibility and increased opportunities for firms in following a strategic course of action, firms often incur extra expense just to keep alternatives open (Harrigan and Newman 1990). Multiple alternatives have the effect of reducing an organization's dependence on any one alliance or course of action. Additionally, although an organization may have many alternatives open, economic constraints make it likely that not all of the opportunities will be pursued. Thus, the number of options available is likely to affect the commitment to any one alliance. Those members with more options available will have more choices for investment and, consequently, will be less dependent on any one alliance and more likely to leave any one alliance, especially when it no longer fits the strategic need of the partner. Thus, dependence on any one alliance will reduce the strategic flexibility firms have in exiting the relationship.

Likewise, partnerships based on dependence may not be conducive to flexibility in modifying the terms of the agreement. When one party is dependent on the other, the other is said to have power in the relationship (Emerson 1962). Because of this, the more powerful partner may have no motivation to adjust to changes. Under this scenario, flexibility of the relationship may not be a result. Thus, the dependence of the partner on the alliance will be negatively related to the strategic flexibility of that alliance, in terms of both modification and exit.

HyPOTHESIS 5a. Dependence is negatively related to the strategic flexibility of an alliance, measured in terms of modification.

HYPOTHESIS 5b. Dependence is negatively related to the strategic flexibility of an alliance, measured in terms of exit.

\section{Sources of Trust}

The construct, trust or trustworthy behavior, is a common element in both transaction cost economics as well as social exchange theory. Behavioral scholars have adopted the assumption that most exchange partners are trustworthy and that trust will exist in exchange relationships even if economic safeguards against opportunism are not in place. However, economic theorists argue that because economic actors have the potential for opportunistic behavior, safeguards must be in place to ensure trustworthy behavior (i.e., lack of opportunistic behavior). While this lack of opportunistic behavior is not consistent with a 
social exchange theory view of trust which argues that trust evolves out of past experience and current interaction (Deutsch 1973, Rempel et al. 1985) and is not the result of economic hostages, both theories share a commonality. Trust, according to social exchange theory, and lack of opportunistic behavior, according to transaction cost economists, have reliability and predictability of action as a basis for their definitions.

Social Exchange Theory and Trust. Lewis and Weigert (1985) contend that trust is characterized by a cognitive "leap" of faith beyond the expectations that reason and experience alone would warrant. Thus, where opportunism might be rationally expected, trust prevails. It should be noted that hostage exchanges in the form of specific assets or other types of economic hostages avoid trust by structuring the transactional context in such a way that opportunism becomes irrational. The importance of this distinction is important to our understanding of trust. Trust, according to social exchange theorists, is not a result of contracts, credible commitments, or hostages because these require no "leap" and are actually more descriptive of situations requiring little or no trust. In other words, activities can be coordinated through either contracts or trust or a combination, but the differences should be kept clear.

The social exchange literature suggests that two main sources of trust exist. One is a result of reputation while the other resides in sharing similar values. The first, reputation, requires knowledge of previous relationships or may develop over time as partners continue to interact. The reputational source of trust involves both previous relations and length of attachment. The second main source of trust, shared values, requires only current knowledge about one's partner to the exchange and may be transmitted through the current exchange process. The sharing of values involves communication as well as an understanding of the goals and values of the partner.

Previous Relations. The knowledge that an organization can be trusted is based, in part, on that organization's reputation. This reputation can be established either through previous relationships or alliances (e.g., Gulati 1995, Hladik 1988) or over time as the length of the attachment between the partners increases (Seabright et al. 1992). Shared experiences between firms can engender trust among the partners, resulting in closer bonds. The idea of trust and commitment emerging from prior contact has been a common theme in much of the literature involving social exchange and trust (e.g., Blau 1964, Cook and Emerson 1978, Lewis and Weigert 1985, Luhman 1979, Zucker 1986), and has been examined in the literature at both the intraorganizational (e.g., McAllister 1995, Zand 1972) and interorganizational levels
(Anderson and Weitz 1989, Gulati 1995, Hladik 1988, Larson 1992, Parkhe 1993, Ring and Van de Ven 1992). The implication of all of these studies is that trust develops between partners over time and is intimately tied to past experiences. This firm-specific information concerning prior exchanges provides data about the trustworthiness of the exchange partner. Similarly, Ring and Van de Ven (1992) propose that reliance on trust between organizations can be expected to emerge only when they have successfully completed transactions in the past and they perceive that the partner has acted equitably. Consequently, it is expected that the existence of previous relationships with the current partner is positively related to trust.

HYPOTHESIS 6. The existence of previous relationships with any partner companies is positively related to to trust among partners in a strategic alliance.

Attachment. Attachment refers to the prior history of a particular exchange relationship. Similar to the arguments for previous relationships over time, as time goes on in a relationship, partners come to know whether the other partner can be trusted. Increased attachment has been found to be positively related to commitment to the relationship with the assumption being that, among other things, trust has developed. Cook and Emerson (1978), in their work on social exchange, argue that attachment is a distinct attribute of interorganizational relationships. Scanzoni (1979) argues that one reason why older dyads continue is that experience breeds trust. Through previous actions, a foundation is laid for trust. Seabright et al. (1992) address the importance of attachments in interorganizational relationships. While not directly testing the impact of attachment on trust, their argument is consistent with that which specifies that trust develops over time. Consequently, it is proposed that attachment will be positively related to trust. The longer the parties have been together in a particular alliance, the more they will trust each other.

HyPOTHESIS 7. Attachment between the partners to the alliance is positively related to trust among partners in a strategic alliance.

Communication. One factor leading to trust is the level of communication between partners. Communication "can be defined broadly as the formal as well as informal sharing of meaningful and timely information between firms" (Anderson and Narus 1990, p. 44). Support for the relationship between communication and trust exists in both intra- and interorganizational research. Interaction frequency was found to be positively related to affect-based trust (McAllister 1995) between managers 
and their peers. Lorenz (1988) argues that personal contact allows for easier exchange of information. This in turn allows the partners to learn about the other person's idiosyncrasies and develop an understanding between the parties. In short, communication allows for the exchange of information such as shared values, goals, and objectives, key factors related to trust. Consequently, it is expected that communication (in quantity and quality) will be positively related to trust.

HypOTHESIS 8. The level and quality of communication between the partners in a strategic alliance is positively related to organizational level trust in the partner company.

Shared Values. While reputation is an important indicator of the trustworthiness of an exchange partner, it is by no means the only indicator. This assumes that partners have transacted in the past. Does this mean that there is no trust possible between those partners exchanging for the first time? Borrowing from the social-psychological literature, trust can also be a function of a person's faith in another. This faith is often a result of shared values (Zucker 1986). Shared values refers to the extent that partners to an exchange have common beliefs regarding the importance of the motives for transacting as well as the goals and objectives of the exchange. Dwyer et al. (1987) theorize that shared values contribute to the development of commitment and trust in marketing relationships. Empirical support for this relationship between shared values and both commitment and trust is found by Morgan and Hunt (1994). Additionally, trust develops in part as a result of a partner's interpretation of his or her counterpart's motives and intentions (Kelley 1979).

Related to the idea of shared values is that of cultural similarity. Zucker (1986) has proposed that one of the three central modes of trust, character-based trust, relies on social or cultural similarity. The argument is that others with social similarity may be sought out for exchanges under the premise that many background understandings will be common to parties to the exchange and, consequently, that the outcomes of the transaction will be more satisfactory to both parties. The background understandings she refers to are similar in concept to the shared values and behavioral norms discussed above. Social similarity, she argues, allows norms to be shared across a group of individuals or firms. With the exception of Gulati (1995) who utilizes Zucker's (1986) theory of cultural similarity, little research has been done that examines the relationship between cultural similarity and trust in strategic alliances. Gulati argues that domestic alliances should exhibit more trust, due to cultural similarity, and would be less likely to need to use equity to structure the alliance relationship. While not specifically testing the relationship between similarity and trust, he does find that international alliances are more likely to be equity based than domestic alliances.

Consequently, it is expected that the existence of shared values between the organizations, in the form of cultural similarity and sharing of goals and objectives, will be positively related to trust.

HYPOTHESIS 9. The existence of shared values between the organizations is positively related to organizational level trust.

Transaction Cost Economics and Trust. In describing trust, Williamson (1993) makes a distinction between calculative, personal, and institutional trust. The first, calculative, refers to a "rational form of trust fostered by mutual hostages and other economic commitments." The second, personal trust, does not depend on calculations of self-interest for its formation or continuation, and applies, according to Williamson, only in personal relationships. Finally, institutional trust derives from the social and organizational embeddedness but in fact, according to Williamson (1993) is calculative as well. Barney and Hansen (1995) describe these first and third types of "calculative" trust as "semi-strong" trust and argue that when the cost of opportunistic behavior is greater than its benefit, it will be in the rational self-interest of exchange partners to behave in a trustworthy manner. That is, trustworthy behavior and, consequently, trust between partners are a result of rational decision making in their own economic interest. Similar to Williamson (1993), this is the type of trustworthy behavior emphasized in most economic models of exchange and has been most commonly referred to as a lack of opportunistic behavior. According to Cummings and Bromiley (1996), part of the reason we may trust our partner is that we know that our partner works within a control system that makes it very hard to benefit from acting opportunistically.

Economists, then, assume the existence of opportunistic behavior in economic partnerships. Thus, when an organization believes that a partner engages in opportunistic behavior, such perceptions will lead to decreased trust. However, as discussed previously, economic constraints such as hostages and balanced asset specificity may serve to decrease the perceived opportunistic behavior of the partners by increasing the reliability and predictability of their behavior. As such, we would expect a positive relationship between these economic constraints and trust between the partners.

HYPOTHESIS 10. Economic commitments in the form of balanced asset specificity are positively related to trust among partners in a strategic alliance. 
HYPOTHESIS 11. Economic commitments in the form of hostages are positively related to trust among partners in a strategic alliance.

Dependence and Trust. A primary consequence of dependence is power. Dependence varies with the value received (i.e., importance) from a partner and inversely with the availability of alternative trading partners (Cook and Emerson 1978). The exercise of power by one partner (based on dependence of the other) may lead to a partner's acquiescence. However, the continuing exercise of power to gain acquiescence will promote dysfunctional conflict and destroy trust (Lusch 1976). As suggested from the above discussion, the relationship between dependence and trust has been discussed in very negative terms. Consequently, it is proposed that dependence will be negatively related to the level of trust between the partners.

HYPOTHESIS 12. Dependence is negatively related to trust among partners in a strategic alliance.

\section{Model Specification, Data Collection, and Research Methods}

\section{Model Specification}

To test the hypotheses in this study, we specified two models using the maximum likelihood estimation procedure in LISREL VIII (Joreskog and Sorbom 1993): one for modification flexibility and another for exit flexibility. Structural equation modeling techniques are considered to be a major component of applied multivariate analysis (Marcoulides 1995). Structural equation modeling (SEM) techniques are particularly useful in theory development because they permit the researcher to propose and subsequently test theoretical propositions about interrelationships among variables in a multivariate setting (Heck et al. 1990). In its broadest sense, SEM is concerned with testing complex models for structure of functional relationships between observed variables and latent (hypothetically existing) variables. The functional relationships are described by parameters that indicate the magnitude of the effect (either direct or indirect) that independent variables have on dependent variables. Thus, a structural model may be viewed as a guide that allows the researcher to assess the relative strength of each variable included in explaining a desired set of outcomes. The models tested in this study were posited a priori to examine the specific factors that impact the flexibility of a strategic alliance in terms of modification and exit.

A structural equation model can be translated in the LISREL program into a mathematical model with two fundamental parts. The first is known as the measurement model. This is the model that specifies the relationships between the observed variables (e.g., four measures of trust) and the underlying constructs they are hypothesized to measure, referred to as latent variables (e.g., overall trust). The second is known as the structural model. The structural portion of the model allows the latent constructs to be tested for relationships that have been theoretically proposed.

Anderson and Gerbing (1988) suggest the use of a twostage approach to structural equation modeling. This allows for a more accurate picture of the relationship between the theoretical constructs without it being blurred with the results of the measurement model. The first stage is to determine the adequacy of the measurement model before analyzing the second part of the model, the structural component. Prior studies by Young and Marcoulides (1997) utilizing this sample found high confirmatory evidence for the measurement model and the observed latent constructs utilized in this study. For this study then, we utilized item parsing by collapsing multi-item measures to create unidimensional measures representing the latent construct. As a consequence, the results presented in this study will emphasize the second stage of structural equation modeling, the structural model. To construct the various factors presented below (and collectively in Figure 1, below), the common method of item parcelling (much like constructing a scale) was used. Item parcelling has multiple advantages over using individual items as indicators (e.g., Rindskopf and Rose 1988). Of key concern for the present investigation, parcelling allows for the estimation of fewer parameters in the measurement model, ensuring that the estimates will be more stable in small samples (West et al. 1995).

The proposed model specifies factors that together comprise visible aspects of organizations that influence strategic alliance flexibility. In this specific case, the outcomes of interest are modification and exit flexibility. The determinants of modification and exit flexibility are conceptualized on the basis of transaction cost economics (i.e., asset specificity, balanced asset specificity, hostages) and social exchange (i.e., trust, dependence) theories. As recommended by Harris and Schaubroeck (1990), multiple observed indicators were used to measure all of the latent variables included in the model (see section titled "Definition and Measurement of the Variables").

\section{Sample}

A sample of high technology strategic alliances occurring during the 1987-1994 period were chosen where at least one of the partners was U.S.-based, the alliance involved research in the area of information technology (IT), and 
the alliance was either a joint development agreement (JDA) - two or more firms working together on new technology or products - or a joint research pact (JRP) - the joint undertaking of research projects with shared resources.

By focusing on IT alliances, this study uses a relatively homogeneous sample which controls for other external factors that might impact the relationships being investigated. The selection of IT JRPs and JDAs was chosen because of the unique nature of their activities and governance. JRPs and JDAs involve a sharing of technology or joint development without the joining of the companies in an equity-type of arrangement such as a joint venture. The unique nature of this sample allows us to focus on strategic alliances where flexibility is considered to be of utmost importance given the dynamic nature of technological and competitive change. The uncertainty associated with $\mathrm{R} \& \mathrm{D}$ alliances involving information technology often requires skills, such as flexibility, that may not be as essential in other types of industries or alliances.

From an initial sample of 291 strategic alliances, a final sample of 132 alliances involving 241 firms resulted, due to the elimination of firms wherein data was not available, the alliances never took place or took on another form such as a licensing agreement, or there was no key informant. Callbacks and refaxing yielded 91 completed surveys (38\% of 241). This response rate is consistent with, or even greater than, research using survey data to examine interorganizational relationships (e.g., Anderson and Narus 1990).

Care was taken in this study to ensure that the informants in this sample of alliance partners were selected properly. However, their knowledge and involvement were assessed via self-reports, which could be a limitation of this sample. In particular, some researchers have questioned the ability of key informants to report validly (e.g., Philips 1981), though others (e.g., Brown et al. 1990) have argued that a single, reliable informant is preferred over multiple respondents with varying familiarity with the phenomenon. To overcome this limitation and to be able to examine the reliability of the responses from the key informant, a shortened version of the questionnaire was sent to secondary informants. An analyses of these questionnaires was conducted to examine the reliability of the primary respondents and found no significant differences between the primary and secondary respondents on the measures used in this study. Consequently, the primary respondent from each company was considered to be a reliable informant.

\section{Definition and Measurement of the Variables}

Table 1 reports the item wording and Cronbach's alphas for the measures used in this study.
Strategic Flexibility. For this study, flexibility consists of both the ability to modify the current relationship as well as the ability to exit an alliance performing poorly. To measure the first type of strategic flexibility, modification, respondents were asked to rate on a seven-point Likert-type scale three statements reflecting the partners' ability to adjust and modify the agreement as needed (Heide and John 1992). These measures were a reliable indicator of the first type of flexibility and were collapsed to form one measure (Cronbach's alpha $=0.81$ ) to be included in the analysis.

For strategic flexibility as measured by exit, only those respondents that rated their company's satisfaction below the mean (41 firms) were included in the analysis. To assess flexibility in terms of the relative ease of exit from an alliance, respondents were asked to rate on a sevenpoint Likert-type scale the probability of their organization terminating the alliance relationship within the next year. In the case where an organization had already terminated the relationship, they were assigned a "seven." As suggested by Parkhe (1993), it is important to assess any possible unanticipated negative or positive consequences of the partnership. Respondents were asked to rate on a seven-point Likert-type scale any unanticipated positive or negative outcomes for their company. Additionally, consistent with Harrigan (1988) and Parkhe (1993), a partner's overall evaluation of the alliance's performance was obtained by asking informants to rate, on a seven-point Likert-type scale, two statements reflecting the performance of the alliance. Each was asked to rate the extent to which the alliance has fulfilled their organization's expectations and the alliance's effectiveness. These measures were collapsed (Cronbach's alpha $=0.74$ ) to get one overall assessment of performance.

Asset Specificity. Informants were asked to categorize the assets their organization contributed to the alliance into intangible (administrative personnel and technical personnel) and tangible (technical equipment, facilities, and financing). Additionally, respondents were requested to indicate for all types of assets contributed, the percentage of those assets that could easily be transferred for use elsewhere. These two sets of measures were collapsed into one: the degree of asset specificity (for both intangible and tangible assets) in the alliance.

Balanced Asset Specificity. Balanced asset specificity represents the degree to which the partners in the alliance have invested equivalent specific assets into the relationship. Respondents were asked to indicate the reciprocal assets invested by their partner in the same manner as above. A calculation was made to compare the balance 
Strategic Flexibility: Modification (Scale 1-7: Strongly Disagree-Strongly Agree)**

1. When an unexpected situation arises, the parties would rather modify the agreement than hold each other to the original terms.

2. Flexibility in response to requests for changes is a characteristic of this alliance.

3. The parties expect to be to make adjustments in the ongoing relationship to cope with changing circumstances.

Strategic Flexibility: Exit

1. What is the probability of your company terminating this alliance within the next year? (Scale 1-7: Very Low-Very High)

2. Performance**

Alliances often result in unexpected outcomes. Some can be negative (e.g., leakage of proprietary information) while others may be positive (e.g., development of unanticipated new market). To what extent has this alliance resulted in:

a. unanticipated positive outcomes for your company? (Scale 1-7: Not at All-Extensively)

b. unanticipated negative outcomes for your company? (Scale 1-7: Not at All-Extensively)*

c. fulfilled expectations? (Scale 1-7: Not at All Satisfied-Completely Satisfied)

d. overall effectiveness (Scale 1-7: Not At All Satisfied-Completely Satisfied)

Asset Specificity

1. Which of the following assets has your company dedicated specifically to this alliance? (Yes/No)

a. Intangible assets (Administrative Personnel and Technical Personnel)

b. Tangible assets (Technical Equipment, Facilities, and Financing)

2. If yes, were the alliance to dissolve today, what percentage of each of your company's assets could be transferred for use elsewhere?

Balanced Asset Specificity

1. Which of the following assets has your partner company dedicated specifically to this alliance? (Yes/No)

a. Intangible assets (Administrative Personnel and Technical Personnel)

b. Tangible assets (Technical Equipment, Facilities, and Financing)

2. If yes, were the alliance to dissolve today, what percentage of each of your partner company's assets could be transferred for use elsewhere?

Hostages (Yes/No)

1. Currently, which of the following types of relationships does your company have with your partner company?

- Trade Association Membership

- Contracting/Licensing

- Manufacturing/Marketing Joint Ventures

- R\&D Joint Ventures

- R\&D Consortia

- Other (Yes/No)

Trust (Scale 1-7: Strongly Disagree-Strongly Agree)**

1. When we encounter difficult and new circumstances, my company does not feel worried or threatened by letting our partner company do what it wants.

2. My company is familiar with the patterns of behavior our partner company has established, and we can rely on them to behave in certain ways.

3. We have found that our partner company is unusually dependable.

4. Our partner company cannot be trusted at times.*

Power/Dependence: Influence (Scale 1-7:No Influence-A Great Deal of Influence)**

1. How much influence does your company have, relative to that of your partner company, on the following decisions?
a. Alliance goals
b. Alliance operating decisions
c. Budget allocations
d. Selection of research projects 
Power/Dependence: Alternatives

1. Does your company currently conduct the same activities conducted by this alliance in any of the following arrangements? (Yes/No)

- Internally

- Licensing

- Joint Venture

- Other Types of Alliances

2. If no for any, please indicate your company's potential for using these arrangements for conducting the alliance's activities. (Scale 1-7: Low Potential-High Potential)*

Power/Dependence: Importance

1. The nature of the activities conducted by this alliance are similar/dissimilar to your company's primary focus? (Scale 17: Similar-Dissimilar)

Previous Relationships

1. Has your company previously been engaged with your partner company in other alliances? (Yes/No)

2. If yes, how many years did the previous alliance last?

\section{Attachment}

1. How long has your company been involved in this alliance? (Measured in months)

Communication (Scale 1-7: Strongly Disagree-Strongly Agree)**

1. We always keep each other informed about events or changes that may affect the other party.

2. It is expected that any information that might help the other party will be provided to them.

3. It is expected that proprietary information will be shared if it can help the other party.

4. Exchange of information in this alliance takes place frequently and informally, not only according to a prespecified agreement.

Shared Values (Scale 1-7: Strongly Disagree-Strongly Agree)**

1. Our goals and objectives for this alliance are shared by our partner company

2. Our partner company had similar motives for forming this alliance.

${ }^{*}$ Reverse Coded

${ }^{\star \star}$ Reliability indicated for these multiple-item measures.

of asset specificity for both intangible and tangible investments by taking the absolute difference of the partners' specific assets invested. Here, a "zero" indicated a perfectly balanced set of investments.

Hostages. Similar to Kogut (1989), hostages was operationalized as concurrent relationships that an organization has, in addition to the focal alliance, with their partner organization. Informants were asked to specify which of five types of relationships their organization concurrently had with their partner company. If any concurrent relationship existed between the partners then a hostage arrangement between the partners was considered to exist and was coded as a "one." When no hostage arrangement existed, a code of "zero" was used.

Trust. Measures of trust were drawn from the literature on both interpersonal trust (Johnson-George and
Swap 1982, Larzelere and Houston 1980, McAllister 1995) and interorganizational trust (Anderson and Narus 1990, Morgan and Hunt, 1994). After modifying the statements to reflect the nature of the alliance activity, respondents were asked to rate, on seven-point Likerttype scale, four statements reflecting their organization's trust in their partner organization. These measures reflected the three components of trust used in much of the interpersonal trust literature (i.e., dependability, predictability, and faith). The measures were collapsed to reflect one overall measure of trust for inclusion in the model (Cronbach's Alpha $=0.86$ ).

Power/Dependence. Using the definition of dependence suggested by Pfeffer and Salancik (1978), our measure of power/dependence is composed of three elements: (1) the influence in the use of the resource, (2) the absence 
of alternatives, both current and potential, and (3) the importance of the resource being obtained. To measure influence, respondents were asked to rate on a seven-point Likert-type scale four statements concerning their organization's influence over the following alliance decisions: goals, operating decisions, budget allocations, and the selection of research projects. These measures were collapsed into one measure of influence to be included in the model (Cronbach's Alpha $=0.82$ )

To measure the absence of alternatives, respondents were asked whether their organization was currently able to conduct the alliance activities in any of four alternative arrangements and they were asked to rate on a sevenpoint Likert-type scale their organization's potential for conducting these activities (if they weren't already doing so).

Importance of the resource being obtained was conceptualized in terms of the criticality of the resource. A resource is considered critical when that resource is a key part of the focal organization's operations or function or to the extent to which the organization requires it for operation or continued survival (Blau 1964, Emerson, 1962, Pfeffer and Salancik 1978) Thus the alliance will be more critical, and therefore more important, to the organization when the alliance is conducting research that is directly related to the organization's primary research interests.

Previous Relationships. Consistent with Gulati (1995) and Anderson and Weitz (1989), respondents were asked whether or not their organization had previously partnered with their current partner. Additionally, this study included another element by asking how long the relationship(s) lasted. The importance of this additional element is clear. A previous short-lived alliance may not have the desired effect as some researchers assume (i.e., increased trust) but may actually act to decrease the trust if the alliance was dissolved prematurely.

Attachment. Attachment refers to the length of the current relationship. Using the same operationalization of attachment as Seabright et al. (1992), respondents were asked to indicate how long (in months) their organization had been involved in the focal alliance.

Communication. The quality of the communication between partners to an exchange is related to the trust that develops in that relationship (Moorman et al. 1993). Consequently, respondents were asked to rate on a sevenpoint Likert-type scale four statements reflecting the quality of communication between the organizations. These measures are consistent with those used by marketing channels researchers (e.g., Heide and John 1992, Mohr and Spekman 1994). Preliminary analyses indicated that these four measures of communication quality were highly related (Cronbach's alpha $=0.89$ ); hence, for further analysis in the overall model, they were collapsed into one variable: communication.

Shared Values. Two separate aspects of this construct were measured. First, consistent with Gulati (1995), we categorize the alliance as either multinational or domestic $(1=$ all partners from the U.S., $0=$ multinational alliance). Consistent with previous research examining the relationship between shared values and trust (Morgan and Hunt 1994), it was requested that the respondent rate on a seven-point Likert-type scale their organization's agreement concerning two statements reflecting the degree to which the partners have a common understanding of the motives for joining, and the goals and objectives of the alliance. These two statements were highly correlated (Cronbach's alpha $=0.91$ ) and were combined into one variable: shared goals. Consequently, the construct shared values is composed of both shared nationality and shared goals.

\section{Findings}

Table 2 shows the means and standard deviations for the measures used in this model.

\section{Assessment of the Structural Model}

Figure 1 (modification flexibility) and Figure 2 (exit flexibility) are the a priori structural models we tested, with significant parameter values indicated. The full results of the structural models are reported in Tables 3 and 4 . The parameter estimates are indices that represent the simultaneous contribution of each latent variable to the model. Also included are the error terms for the structural equations. In standardized form, error coefficients represent the proportion of variance in each equation not accounted for in the structural model. The error coefficient for modification flexibility is 0.26 and 0.37 for exit flexibility.

Because our models were defined a priori, our primary interest is in the model fit. Once the model fit is determined, the significance of the various parameter estimates can be ascertained (Marcoulides 1989). Without a significant model fit, however, we would have to reconceptualize our models. The assessment of the fit of the models is revealed by examining the goodness of fit index (GFI $=0.93$ for modification and 0.90 for exit), the adjusted goodness of fit index (AGFI $=0.90$ for modification and 0.88 for exit), and the normed index (NFI $=0.95$ for modification and 0.92 for exit). It is generally recognized that GFI, AGFI, and NFI values above 0.90 indicate a satisfactory model fit. For these models, these indices all suggest a good model fit. Because the models were determined to fit the data reasonably well, we can now assess more thoroughly the significance of the empirical validation of our hypotheses. 
Table 2 Descriptive Statistics and Correlations Among Constructs

\begin{tabular}{|c|c|c|c|c|c|c|c|c|c|c|c|c|c|c|c|}
\hline Construct & Mean & S.D. & 1 & 2 & 3 & 4 & 5 & 6 & 7 & 8 & 9 & 10 & 11 & 12 & 14 \\
\hline \multicolumn{16}{|l|}{ Strategic Flexibility } \\
\hline 1. Modification & 4.24 & 1.66 & & & & & & & & & & & & & \\
\hline 2. Exit & 4.37 & 1.97 & 0.20 & & & & & & & & & & & & \\
\hline \multicolumn{16}{|l|}{ Transaction Cost Economics } \\
\hline 3. Asset Specificity-Intangible & 36.41 & 25.14 & -0.37 & -0.63 & & & & & & & & & & & \\
\hline 4. Asset Specificity-Tangible & 29.25 & 22.36 & -0.33 & -0.31 & 0.19 & & & & & & & & & & \\
\hline \multicolumn{16}{|c|}{ 5. Balanced'Asset Specificity_ } \\
\hline Intangible & 28.78 & 13.31 & 0.42 & 0.13 & 0.18 & 0.24 & & & & & & & & & \\
\hline \multicolumn{16}{|c|}{ 6. Balanced Asset Specificity_- } \\
\hline Tangible & 32.24 & 22.11 & 0.14 & 0.19 & 0.19 & 0.21 & 0.26 & & & & & & & & \\
\hline 7. Hostages & 0.84 & 0.37 & 0.55 & 0.11 & 0.22 & 0.17 & 0.12 & 0.08 & & & & & & & \\
\hline \multicolumn{16}{|l|}{ Social Exchange Theory } \\
\hline 8. Trust & 4.09 & 1.44 & 0.69 & 0.47 & -0.02 & 0.11 & 0.33 & 0.29 & 0.46 & & & & & & \\
\hline 9. Influence & 3.88 & 1.42 & 0.40 & 0.06 & -0.13 & -0.14 & -0.08 & 0.09 & 0.07 & 0.40 & & & & & \\
\hline 10. Alternatives & 3.19 & 2.04 & 0.13 & 0.32 & 0.07 & 0.18 & 0.13 & $0.19-$ & -0.01 & 0.15 & 0.08 & & & & \\
\hline 11. Importance & 4.32 & 1.84 & 0.07 & 0.45 & 0.02 & 0.08 & 0.09 & $0.13-$ & -0.24 & 0.11 & 0.10 & 0.12 & & & \\
\hline 12. Previous Relations & 5.12 & 3.31 & 0.11 & -0.27 & 0.06 & 0.10 & -0.01 & 0.21 & 0.27 & 0.17 & 0.11 & -0.13 & -0.28 & & \\
\hline 13. Attachment & 52.46 & 36.20 & 0.34 & -0.44 & -0.01 & 0.05 & 0.03 & -0.06 & 0.09 & $0.04-$ & -0.01 & -0.07 & 0.05 & -0.22 & \\
\hline 14. Communication & 4.79 & 1.50 & 0.60 & 0.51 & -0.14 & 0.04 & -0.23 & -0.16 & 0.35 & 0.79 & 0.18 & 0.04 & -0.17 & 0.17 & 0.09 \\
\hline 15. Shared Values & 4.82 & 1.53 & 0.71 & 0.42 & -0.16 & 0.21 & 0.02 & 0.17 & 0.51 & 0.77 & 0.28 & 0.08 & -0.15 & 0.21 & -0.040 .46 \\
\hline
\end{tabular}

Assessment of the Hypothesized Relationships

Influence of Transaction Cost Economics. As shown in Figures 1 and 2, the results for transaction cost economic theory show mixed results. Contrary to Hypothesis 1a, asset specificity is negatively related to strategic flexibility of the alliance, measured in terms of modification. Additionally, asset specificity is negatively related to the strategic flexibility of the alliance, measured in terms of exit, providing support for Hypothesis $1 b$.

Consistent with Hypothesis 2, balanced asset specificity (intangible assets) is positively related to the strategic flexibility of an alliance, measured in terms of modification. This result provides support for the role of mutual commitments in providing an incentive to maintain the relationship through modification or mutual adjustment. Additionally, this supports the previous discussion that suggested intangible assets are more likely to provide an even stronger lock-in to the relationship than tangible assets.

For the relationship between hostages and strategic flexibility, results indicate that the existence of hostage arrangements was positively related to strategic flexibility of the alliance, measured in terms of modification, thus confirming Hypothesis 3a. However, we found no support for Hypothesis $3 b$ in which we proposed a negative relationship between the existence of hostages and strategic flexibility, measured in terms of exit.
Influence of Social Exchange Theory. Factors suggested by social exchange theory have a significant influence on strategic flexibility. Trust is significant and positively related to modification flexibility, strongly supporting Hypothesis 4a. Likewise, we found a significant and positive relationship between trust and flexibility, measured in terms of exit, providing strong support for Hypothesis $4 b$.

The results for the role of dependence on the flexibility of an alliance provide strong support for Hypotheses 5a and $5 \mathrm{~b}$, which proposed that dependence is negatively related to strategic flexibility in terms of modification (Hypothesis 5a) and exit (Hypothesis 5b). Two of the three measures of dependence, influence and alternatives, were significant and negatively related to modification flexibility, while alternatives and importance were significant and negatively related to flexibility, measured in terms of exit. The six significant links affirm the importance of social exchange theory factors in influencing strategic flexibility in alliances.

\section{Sources of Trust}

Social Exchange Theory and Trust. In examining sources of trust in terms of social exchange theory, the findings indicate that communication and shared values were significant factors influencing trust. Previous relations and attachment, however, were not significantly re- 
Figure 1 Structural Model of Modification Flexibility

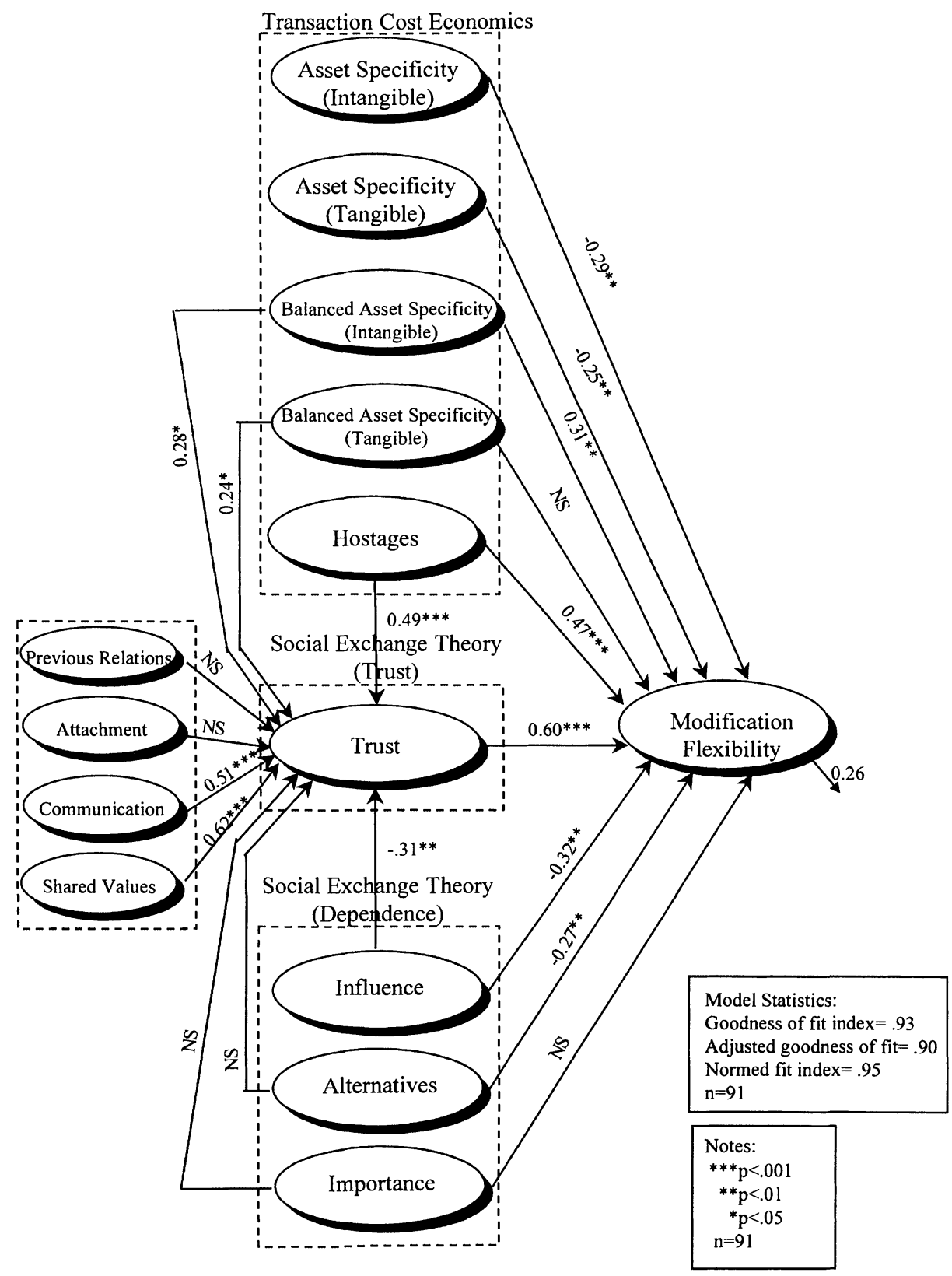

lated to trust, disproving Hypothesis 6, in which it was proposed that the existence of previous relationships with the current partner(s) would be positively related to trust among partners in a strategic alliance. Attachment was also found not to be related to trust. In other words, the length of time that partner organizations have been together had little or no impact on the trust developed between the organizations. This is inconsistent with predictions in Hypothesis 7. The results indicate support for
Hypothesis 8 . The level and quality of communication between the partner organizations was found to be positively related to trust in the partner company. Hypothesis 9 was confirmed in the analysis. The shared values between the organizations was found to be positively related to trust.

Transaction Cost Economics and Trust. Results of the proposed relationships among the theoretical determinants of flexibility revealed an interesting set of 


\section{Figure 2 Structural Model of Exit Flexibility}

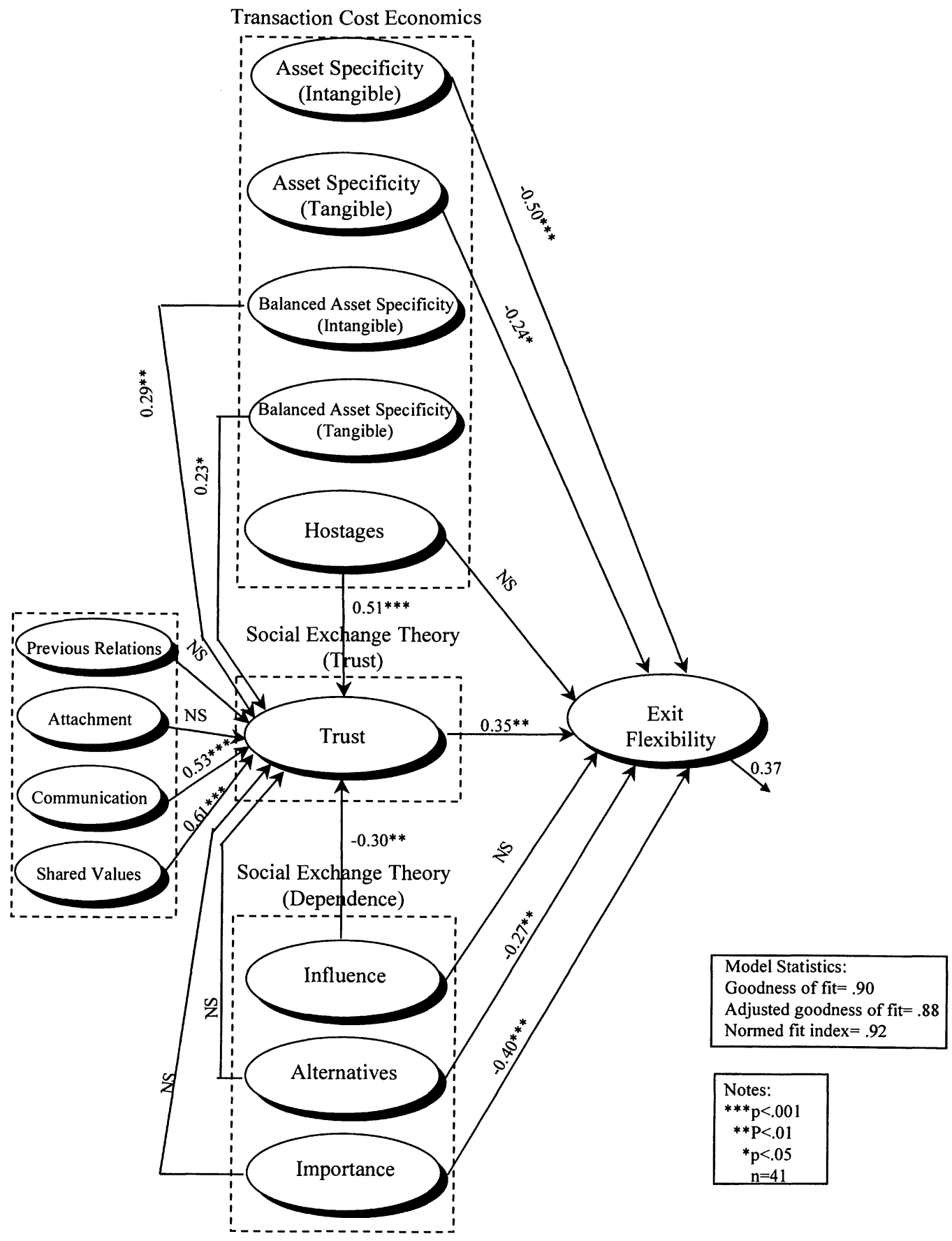

interrelationships. In examining the relationship between factors suggested by transaction cost economics and trust, as shown in both Figures 1 and 2, we found a positive relationship between three factors suggested from transaction cost economic theory-balanced asset specificity (both tangible and intangible), hostages, and trust. This provides support for Hypotheses 10 and 11, which proposed a positive relationship between economic commitments in the form of balanced asset specificity and hostages and trust between the partners in a strategic alliance. 
Dependence and Trust. The results examining the relationship between dependence and trust provide support for Hypothesis 12, which proposed a negative relationship between dependence and trust. Specifically, a negative relationship was found between one specific measure of dependence, influence on decision making in the alliance, and trust between the partners.

\section{Discussion}

Exploring the influence of transaction cost economics and social exchange theory on the strategic flexibility of alliances involving joint research pacts and joint development agreements showed that, in general, factors from transaction cost economics provided flexibility in modification but not in exit. Generally, trust was found to be positively related to flexibility while the other component of social exchange theory, dependence, was found to be negatively related to the strategic flexibility of the alliance.

This study found mixed support for the role of transaction cost economics in the strategic flexibility of an alliance. The investment of specific assets, both tangible and intangible, was found to have a detrimental impact on the strategic flexibility of alliance relationships. This provides evidence of the inertia or lock-in associated with the commitment of resources that have little or no use in other settings and is consistent with results found by researchers examining forces leading to continuity in the relationship. However, when the assets contributed by both parties are considered, a different result is found. When both parties have equivalent specific assets at stake, they are likely to strive to modify the arrangement to keep it going. And yet, when the alliance does not satisfy the partner, these assets will serve to lock the partners into the relationship. Previous research has not adequately explored this construct, which is unique to dyadic relationships. The significant results indicate that it is important to consider both partners' contributions. The relative importance of the assets contributed may serve to align the interests of the parties involved. This alignment of interests cannot be determined by looking at only one side of the assets contributed. Similarly, hostages, which have been described as another type of economic commitment, will provide flexibility in modifying the arrangement, but no significant relationship was found with regard to exit barriers. Thus, while mutual economic hostages, in the form of specific assets or current relationships with the partner, encourage partners to modify the current arrangement to protect their investments, the flexibility to exit is not provided. This last finding is in direct contrast with
Table 3 Parameter Estimates for Structural Model of Modification Flexibility (Figure 1)

\begin{tabular}{|c|c|c|c|}
\hline \multirow[b]{2}{*}{ Following/Leading Constructs } & \multicolumn{3}{|c|}{ Hypothesized Standardized } \\
\hline & Sign & Solution & t-value \\
\hline \multicolumn{4}{|l|}{ Modification Flexibility } \\
\hline Asset specificity (Intangible) & + & -0.29 & $3.23^{\star \star}$ \\
\hline Asset specificity (Tangible) & + & -0.25 & $2.83^{\star \star}$ \\
\hline $\begin{array}{l}\text { Balanced asset specificity } \\
\text { (Intangible) }\end{array}$ & + & 0.31 & $3.84^{\star \star}$ \\
\hline $\begin{array}{l}\text { Balanced asset specificity } \\
\text { (Tangible) }\end{array}$ & + & 0.11 & 1.01 \\
\hline Hostages & + & 0.47 & $4.49^{\star \star \star}$ \\
\hline Trust & + & 0.60 & $5.35^{\star \star \star}$ \\
\hline \multicolumn{4}{|l|}{ Dependence } \\
\hline Influence & - & -0.32 & $3.912^{* \star}$ \\
\hline Alternatives & - & -0.27 & $3.011^{* *}$ \\
\hline Importance & - & 0.15 & 1.74 \\
\hline \multicolumn{4}{|l|}{ Trust } \\
\hline Previous Relations & + & 0.14 & 1.59 \\
\hline Attachment & + & 0.04 & 0.48 \\
\hline Communication & + & 0.51 & $4.87^{\star * *}$ \\
\hline Shared Values & + & 0.62 & $5.62^{\star \star *}$ \\
\hline $\begin{array}{l}\text { Balanced asset specificity } \\
\text { (Intangible) }\end{array}$ & + & 0.28 & $3.11^{\star *}$ \\
\hline $\begin{array}{l}\text { Balanced asset specificity } \\
\text { (Tangible) }\end{array}$ & + & 0.24 & $2.793^{*}$ \\
\hline Hostages & + & 0.49 & $4.72^{\star \star \star}$ \\
\hline \multicolumn{4}{|l|}{ Dependence } \\
\hline Influence & - & -0.31 & $3.839^{\star \star}$ \\
\hline Alternatives & - & 0.12 & 1.22 \\
\hline Importance & - & 0.09 & 0.90 \\
\hline
\end{tabular}

Kogut (1989), who found a positive relationship between the existence of hostages and the continuation of the focal alliance. However, Kogut (1989) did not examine continuation in terms of flexibility to exit the relationship when it may no longer satisfy the partner, but rather considered total exiting firms.

Strong relationships were found for the role of social exchange theory in explaining the flexibility of an alliance. Trust was found to be related to flexibility in modifying the current arrangement and even in exiting a poorly performing alliance. This result is consistent with those researchers who have argued for the role of trust in developing adaptable arrangements. Here, adaptability 
may go so far as to allow partners to dissolve the current relationship in favor of a later more effective arrangement.

Consistent with arguments in the literature on dependence, this study found a negative relationship between a partner's dependence on the alliance and the flexibility of the alliance. Specifically, fewer alternatives for conducting the alliance's activities and low influence in decision making were related to lower flexibility. This result is consistent with Harrigan and Newman (1990), who argued that alternatives reduce dependence on any one course of action and that firms may incur additional expenses to keep these alternatives open.

In examining the various sources of trust suggested by transaction cost economics and social exchange theory, this study found that trust, or the predictability of one's behaviour, is associated with the level of economic commitments in the form of balanced assets invested and hostages. In other words, partners with similar assets at stake, and those with other current relationships with their partner, are more likely to be able to rely on the behavior of their partner. This is consistent with Cummings and Bromiley (1996), who argue that incentive and control systems constrict the behavior of the partners, thereby producing a trusting relationship. Likewise, as suggested by social exchange theory, the quality of communication and the existence of shared values between the partners is positively related to trust. This type of trust is similar to the "strong form" discussed by Barney and Hansen (1995).

In summary, it is important to understand the implications of the various theories in addressing flexibility. Consistent with transaction cost theory, as well as evidenced in many current alliances, commitments, or longlived alliances are often manipulated by demanding high mutual investment of resources, by involving relationship-specific assets, or by taking other economic "hostages" (Williamson 1985). However, these findings suggest that economic commitments may tend to create organization inertia and undermine autonomy and flexibility. Consequently, asset specificity and dependence may need to be minimal in certain relationships because of the desirability to have highly versatile and flexible alliances, particularly in very uncertain environments. Thus, the flexible strategic alliance may need to make less use of capital and resource dependencies to obtain commitment and may instead rely on trust in structuring the relationship, as social exchange theory suggests.

This study makes several contributions to the literature on the effective use of strategic alliances for competing in uncertain and turbulent environments. First, this study
Table 4 Parameter Estimates for Structural Model of Exit Flexibility (Figure 2)

\begin{tabular}{|c|c|c|c|}
\hline \multirow[b]{2}{*}{ Following/Leading Constructs } & \multicolumn{3}{|c|}{ Hypothesized Standardized } \\
\hline & Sign & Solution & $\mathrm{t}$-value \\
\hline \multicolumn{4}{|l|}{ Exit Flexibility } \\
\hline Asset specificity (Intangible) & - & -0.50 & $4.53^{\star \star \star}$ \\
\hline Asset specificity (Tangible) & - & -0.24 & $2.61^{*}$ \\
\hline Hostages & - & 0.09 & 0.79 \\
\hline Trust & + & 0.35 & $3.89^{\star \star}$ \\
\hline \multicolumn{4}{|l|}{ Dependence } \\
\hline Influence & - & 0.08 & 0.71 \\
\hline Alternatives & - & -0.27 & $2.73^{* *}$ \\
\hline Importance & - & -0.40 & $4.34^{\star \star \star}$ \\
\hline \multicolumn{4}{|l|}{ Trust } \\
\hline Previous Relations & + & 0.12 & 1.03 \\
\hline Attachment & + & 0.05 & 0.44 \\
\hline Communication & + & 0.53 & $4.79^{\star \star \star}$ \\
\hline Shared Values & + & 0.61 & $5.21^{\star \star \star}$ \\
\hline $\begin{array}{l}\text { Balanced asset specificity } \\
\text { (Intangible) }\end{array}$ & + & 0.29 & $3.01^{\star *}$ \\
\hline $\begin{array}{l}\text { Balanced asset specificity } \\
\text { (Tangible) }\end{array}$ & + & 0.23 & $2.42^{\star}$ \\
\hline Hostages & + & 0.51 & $4.60^{\star \star \star}$ \\
\hline \multicolumn{4}{|l|}{ Dependence: } \\
\hline Influence & - & -0.30 & $3.15^{\star \star}$ \\
\hline Alternatives & - & 0.11 & 0.91 \\
\hline Importance & - & 0.10 & 0.79 \\
\hline
\end{tabular}

utilizes factors from both transaction cost economic theory and social exchange theory to provide a more thorough understanding of flexibility in strategic alliances. Secondly, this study is the first to examine strategic flexibility in a setting involving two important and widely used types of strategic alliances, joint development agreements and joint research pacts. Additionally, it is the first to examine two important dimensions of strategic flexibility in alliances, the ability to modify the arrangement and the ability to exit the relationship when the alliance is performing poorly. Finally, this study examines important interrelationships among the determinants of flexibility suggested by transaction cost economics and social exchange theory. Specifically, it explores the sources of trust, or trusting behavior, suggested by both transaction cost economic theory and social exchange theory.

\section{References}

Aaker, D., B. Mascarenhas. 1984. The need for strategic flexibility. $J$. Bus. Strategy 5 74-82. 
Anderson, E., B. Weitz. 1989. Determinants of continuity in conventional industrial channel dyads. Marketing Sci. 8 310-323.

Anderson, J., D. Gerbing. 1988. Structural equation modeling in practice: A review and recommended two-step approach. Psych. Bull. 103 411-423.

—, J. Narus. 1990. A model of distributor firm and manufacturer firm working relationships. J. Marketing 54 42-58.

— T. Overton. 1977. Estimating nonresponse bias in mail surveys. J. Marketing Res. 51 71-86.

Bahrami, H. 1992. The emerging flexible organization: Perspectives from Silicon Valley. California Management Rev. 34 33-51.

Balakrishnan, S., M. Koza. 1995. An information theory of joint ventures. Adv. Global High-Tech. Management 5 59-72.

$\rightarrow$ Barney, J. 1990. The debate between traditional management theory and organizational economics: Substantial differences or intergroup conflict? Acad. Management Rev. 15 382-393.

- M. A. Hansen. 1995. Trustworthiness as a source of competitive advantage. Strategic Management J. 15 175-190.

_-, W. G. Ouchi. 1986. Organizational Economics. Jossey-Bass, San Francisco.

Blau, P. 1964. Exchange and Power in Social Life. John Wiley and Sons, New York.

$\rightarrow$ Bradach, J., R. Eccles. 1989. Price, authority, and trust: From ideal types to plural forms. Ann. Rev. Soc. 15 97-118.

Brown, J., R. Lusch, H. Koenig, T. Kroeten, S. Pharr. 1990. Using key informants in marketing channels research: A critique and some preliminary guidelines. G. Frazier, ed. Advances in Distribution Channel Research. JAI Press, Greenwich, CT.

Buckley, P., M. Casson. 1988. A theory of cooperation in international business. F. Contractor, P. Lorange, eds. Cooperative Strategies in International Business: Joint Ventures and Technology Transfers Between Firms. Lexington Books, New York. 31-53.

$\rightarrow$ Cook, K. 1977. Exchange and power in networks of interorganizational relations. The Soc. Quart. 18 62-82.

$-\rightarrow-$, R. Emerson. 1978. Power, equity and commitment in exchange relationships. Amer. Soc. Rev. 43 721-739.

$\rightarrow$ Crocker, K., S. Masten. 1988. Mitigating contractual hazards: Unilateral options and contract length. Rand J. Econom. 19 (3) 327343.

Cummings, L., P. Bromiley. 1996. The organizational trust inventory. Roderick Kramer, Tom Tyler, eds. Trust in Organizations: Frontiers of Theory and Research. Sage, Thousand Oaks, CA.

Deutsch, M. 1973. Me Resolution of Conflict. Yale University Press, New Haven, CT.

Dodgson, M. 1993. Learning, trust and technological collaboration. Human Relations 46 77-95.

$\rightarrow$ Donaldson, L. 1990. The ethereal hand: Organizational economics and management theory. Acad. Management Rev. 15 369-381.

$\rightarrow$ Doz, Y. 1996. The evolution of cooperation in strategic alliances: Initial conditions or learning processes. Strategic Manangement $J$. 17 55-83.

Duncan, R. 1976. The ambidextrous organization: Designing dual structures for innovation. R. Kilman, L. Pondy, D. Slevin, eds. The Management of Organizational Design, vol. 1. Elsevier Science Publishing Co., New York.

Dwyer, P., H. Schurr, Sejo Oh. 1987. Developing buyer-seller relationships. J. Marketing 51 11-27.
Emerson, R. 1962. Power-dependence relations. Amer. Soc. Rev. $271-$ 41.

Evans, S. 1991. Strategic flexibility for high technology maneuvers: A conceptual framework. J. Management Stud. 28 69-89.

Fiegenbaum, A., A. Karnani. 1991. Output flexibility-A competitive advantage for small firms. Strategic Management J. 12 101-114.

Ghemawat, P. 1991. Commitment: The Dynamic of Strategy. The Free Press, New York.

Graham J. 1988. Deference given the buyer: Variations across twelve cultures. F. Contractor, P. Lorange, eds. Cooperative Strategies in International Business: Joint Ventures and Technology Transfers Between Firms, Lexington Books, New York. 473-485.

Granovetter, M. 1985. Economic action and social structure: The problem of embeddedness. Amer. J. Soc. 91 481-510.

Gulati, R. 1995. Does familiarity breed trust? The implications of repeated ties for contractual choice in alliances. Acad. Management J. 38 85-112.

Hagedoorn, G., J. Schakenraad. 1992. Leading companies and networks of strategic alliances in information technologies. Res. Policy 21 163-190.

,- 1994 . The effect of strategic technology alliances on company performance. Strategic Management J. 15 291-309.

Harrigan, K. 1985. Strategies for Joint Ventures. Lexington Books, Lexington, MA.

- 1986. Managing for Joint Venture Success. Lexington Books, Lexington, MA.

- 1988. Strategic alliances and partner asymmetries. F. Contractor, P. Lorange, eds. Cooperative Strategies in International Business: Joint Ventures and Technology Transfers Between Firms. Lexington Books, New York. 205-226.

— W. Newman. 1990. Bases of interorganization co-operation: Propensity, power, persistence. J. Management Stud. 27 417-435.

Harris, M. M., J. Schaubroeck. 1990. Confirmatory modeling in organizational behavior/human resource management: Issues and applications. J. Management 16 337-360.

Heck, R. H., T. J. Larsen, G. A. Marcoulides. 1990. Instructional leadership and school achievement: Validation of a causal model. $E d$. Admin. Quart. 25 (2) 94-125.

Heide, J. 1994. Interorganizational governance in marketing channels. J. Marketing 58 71-85.

— G. John. 1988. The role of dependence balancing in safeguarding transaction-specific assets in conventional channels. J. Marketing 5 20-35.

,- 1990 . Alliances in industrial purchasing: the determinants of joint action in buyer-supplier relationships. J. Marketing Res. 28 24-36.

, - 1992. Do norms matter in marketing relationships? J. Marketing 56 32-44

Hladik, K. 1988. R\&D and international joint ventures. F. Contractor, P. Lorange, eds. Cooperative Strategies in International Business: Joint Ventures and Technology Transfers Between Firms, Lexington Books, New York. 187-203.

Johnson-George, C., W. Swap. 1982. Measurement of specific interpersonal trust: Construction and validation of a scale to assess trust in a specific other. J. Personality Soc. Psych. 43 1306-1317.

Jones, G. 1983. Transaction costs, property rights and organizational culture: An exchange perspective. Admin. Sci. Quart. 28 454-467. 
Joreskog, K., D. Sorbom. 1993. LISREL VIII. Scientific Software, Mooreville, IN.

Katz, M. 1989. Vertical contractual relations. R. Schmalensee, R. Willig, eds. Handbook of Industrial Organization, vol. 1. Elsevier, New York. 655-721.

Kelley, H. 1979. Personal Relationships: Their Structures and Processes Erlbaum, Hillsdale, NJ.

Kelly, D., T. Amburgey. 1991. Organization inertia and momentum: A dynamic model of strategic change. Acad. Management J. 3 591-612.

Klein, B., R. Crawford, A. Alchian. 1978. Vertical integration, appropriable rents, and the competitive contracting process. J. Law Econom. 21 297-326.

$\rightarrow$ Kogut, B. 1989. The stability of joint ventures: Reciprocity and competitive rivalry. The J. Indust. Econom. 38 183-199.

$\rightarrow \rightarrow$. 1991. Joint ventures and the option to expand and acquire. Management Sci. 37 19-33.

Koza, M., A. Lewin. 1998. The co-evolution of strategic alliances. Organ. Sci. 9 255-264.

$\rightarrow$ Larson, A. 1992. Network dyads in entrepreneurial settings: A study of the governance of exchange relationships. Admin. Sci. Quart. 37 76-104.

Larzelere, R., T. Huston. 1980. The dyadic trust scale: Toward understanding interpersonal trust in close relationships. J. Marriage and Family 42 595-604.

Lei, D., J. Slocum. 1992. Global strategy, competence building and strategic alliances. California Management Rev. 35 81-97.

$\rightarrow$ Levine, S., P. White. 1961. Exchange as a conceptual framework for the study of interorganizational relationships. Admin. Sci. Quart. 5 583-601.

$\rightarrow$ Lewis, J., A. Weigert. 1985. Trust as reality. Soc. Forces 63 967-985.

Lorenz, E. 1988. Neither friends nor strangers: Informal networks of subcontracting in French industry. Gambetta, D., ed. Trust. Basil Blackwell, New York. 194-210.

Luhman, N. 1979. Trust and Power. John Wiley, New York.

- 1988. Familiarity, confidence, trust: Problems and alternatives. D. Gambetta, ed., Trust, Basil Blackwell, New York, 94-107.

Lusch, R. 1976. Sources of power: Their impact on intrachannel conflict. J. Marketing Res. 13 382-390.

Marcoulides, G. A. 1995. Structural equation modeling. Decision Line 26 (5) 23-26.

- 1989. Structural equation modeling techniques for scientific research. J. Bus. Soc. 2(2) 130-138.

$\longrightarrow$, R. H. Heck. 1993. Organizational culture and performance: Proposing and testing a model. Organ. Sci. 4(2) 209-225.

$\rightarrow$ McAllister, D. 1995. Affect and cognition-based trust as foundations for interpersonal cooperation in organizations. Acad. Management J. 38 24-59.

Mody, A. 1993. Learning through alliances. J. Econom. Behavior Organ. 20 151-170.

Mohr, I., R. Spekman. 1994. Characteristics of partnership success: partnership attributes, communication, behavior and conflict resolution techniques. Strategic Management J. 15 135-152.

Moorman, C., R. Deshpande, G. Zaltman. 1993. Factors affecting trust in market research relationships. J. Marketing 57 81-101.

Morgan, R., S. Hunt. 1994. The commitment-trust theory of relationship marketing. J. Marketing 58 20-38.
Niederkofler, M. 1991. The evolution of strategic alliances: Opportunism for managerial influence. J. Busi. Venturing 6 237-257.

ver, C. 1990. Determinants of interorganizational relationships: Integration and future directions. Acad. Management Rev. 15 241265.

1991. Network relations and loss of organizational autonomy. Human Relations 44 943-996.

Olk, P., C. Young. 1997. Why members stay or leave an R\&D consortium: Performance and conditions of membership as determinants of continuity. Strategic Management J. 18 855-877.

$\rightarrow$ Parkhe, A. 1993. Strategic alliance structuring: A game theoretic and transaction cost examination of interfirm cooperation. Acad. Management J. 36 794-829.

Perrow, C. 1981. Markets, hierarchies and hegemony: A critique of Chandler and Williamson. A. Van de yen, J. Joyce, eds. Perspectives in Organization Design and Behavior. John Wiley and Sons, New York. 371-386.

Pfeffer, J., G. R. Salancik. 1978. The External Control of Organizations. Harper Row, New York.

Philips, L. 1981. Assessing measurement error in key informants reports. J. Marketing Res. 28 395-415.

Porter, M., M. B. Fuller. 1986. Coalitions and global strategy. M. Porter, ed. Competition in Global Industries. HBS Press, Boston. 315-344.

Provan, K., J. Gassenheimer. 1994. Supplier commitment in relational contract exchanges with buyers: A study of interorganizational dependence and exercised power. J. Management Stud. 31 5568.

Reich, R., E. Mankin. 1986. Joint ventures with Japan give away our future. Harvard Bus. Rev. 64 77-86.

Rempel, J., J. Holmes, M. Zanna. 1985. Trust in close relationships. $J$. Personality Soc. Psych. 49 95-112.

Rindskorpf, D., T. Rose. 1988. Some theory and application of confirmatory second-order factor analysis. Multivariate Behavioral Res. 23 51-67.

$\rightarrow$ Ring, P., A. Van de Ven. 1994. Developmental processes of cooperative interorganizational relationships. Acad. Management Rev. 19 90-118.

Scanzoni, J. 1979. Social exchange and behavioral interdependence. R. Burgess, T. Huston, eds. Social Exchange in Developing Relationships Academic Press, New York, 61-98.

Seabright, M., D. Levinthal, M. Fichman. 1992. Role of individual attachments in the dissolution of interorganizational relationships. Acad. Management J. 35 122-160.

Sherman, S. 1992. Are strategic alliances working? Fortune (September) $77-78$.

Volberda, H. W. 1996. Toward the flexible form: How to remain vital in hypercompetitive environments. Organ. Sci. 7(4) 359-374.

West, S. G., J. F. Finch, P. J. Curran. 1995. Structural equation modeling with nonnormal variables: Problems and remedies. R. H. Hoyle, ed. Structural Equation Modeling: Concepts, Issues, and Applications. Sage Publications, Thousand Oaks, CA.

Williamson, O. 1993. Calculativeness, trust, and economic organization. J. Law Econom. 36 453-486. 
$-\rightarrow$. 1983. Credible commitments: Using hostages to support exchange. Amer. Econom. Rev. 73 519-539

- 1985. The Economic Institutions of Capitalism. Free Press, New York.

Wolff, M. 1994. Building trust in alliances. Res. Tech. Management 37 12-15.

Young, C., G. Marcoulides. 1997. Using item-parcelling to examine a model of strategic alliance commitment. Presented at the Western Decision Sciences Meeting, Hawaii.

Zaheer, A., N. Venkatraman. 1995. Relational governance as an inter- organizational strategy: An empirical test of the role of trust in economic exchange. Strategic Management J. 16 373-392.

- B. McEvily, V. Perrone. 1998. Does trust matter? Exploring the effects of interorganizational and interpersonal trust on performance. Organ. Sci. 9 141-159.

Zand, D. 1972. Trust and managerial problem solving. Admin. Sci. Quart. 17 229-239.

Zucker, Lynne 1986. Production of trust: Institutional sources of economic structure, 1840-1920. Res. in Organ. Behavior. 8 53-111.

Accepted by Mitchell Koza; received March 8, 1998. This paper has been with the authors for one revision. 